Notas 



\title{
WHY BITCOIN CAN NEVER BE MONEY
}

\author{
CHRIS LEROUX*
}

Fecha de recepción: 30 de marzo de 2014.

Fecha de aceptación: 1 de junio de 2014.

\section{I \\ ORIGIN OF MONEY AS THE MOST SALEABLE GOOD}

In On the Origins of Money (1892), Carl Menger explains that in a barter situation, some commodities are more commonly demanded than others, are more saleable. In order to overcome the double coincidence of wants, people naturally begin trading their goods first for a more saleable good in order to then trade for their final objective. Menger (1892) describes it thus, «Men have been led, with increasing knowledge of their individual interests, each by his own economic interests, without convention, without legal compulsion, nay, even without any regard to the common interest, to exchange goods destined for exchange (their "wares") for other goods equally destined for exchange, but more saleable.» Ludwig von Mises restated the same insight in Human Action (1940), "[Money] is the most marketable good which people acquire because they want to offer it in later acts of interpersonal exchange. Money is the thing which serves as the generally accepted and commonly used medium of exchange.»

As ever more people discovered the advantages of using a more saleable good in indirect exchange, one commodity became increasingly adopted until it eventually became money, the most marketable of all goods, the good that can generally be traded for all other goods within the market. As Menger said (1892), «And so it has come to pass, that as man became increasingly conversant

\footnotetext{
* chrisdleroux@gmail.com.
} 
with these economic advantages... those commodities, which relatively to both space and time are most saleable, have in every market become the wares, which it is not only in the interest of every one to accept in exchange for his own less saleable goods, but which also are those he actually does readily accept.»

Mises also describes the process in The Theory of Money and Credit (1912), "Whenever a direct exchange seemed out of the question, each of the parties to a transaction would naturally endeavour to exchange his superfluous commodities, not merely for more marketable commodities in general, but for the most marketable commodities; and among these again he would naturally prefer whichever particular commodity was the most marketable of all. The greater the marketability of the goods first acquired in indirect exchange, the greater would be the prospect of being able to reach the ultimate objective without further manœuvring. Thus there would be an inevitable tendency for the less marketable of the series of goods used as media of exchange to be one by one rejected until at last only a single commodity remained, which was universally employed as a medium of exchange; in a word, money.»

This understanding of money's defining characteristic as the most saleable, most marketable commodity is crucial since money serves as the common denominator for all exchanges. Indeed Menger said (1892), «The theory of money necessarily presupposes a theory of the saleableness of goods» and «Money has not been generated by law. In its origin it is a social, and not a state institution. Sanction by the authority of the state is a notion alien to it.» Money developed organically. No one invented it. No one designed it. Over time, one commodity simply became more saleable than all others as a result of the combined voluntary interactions of all consumers in the market. Money was selected by the entire market from among pre-existing commodities, not from any individual's assessment of subjective marginal utility but by the interactions of all consumers.

Clearly not all mediums of exchange are money, the most saleable good in the market, though money is a medium of exchange, the generally accepted medium of exchange. Not all mediums of exchange offer equal marketability across the entire 
market. A few people may use a medium, a thousand people, or even a million people, and still it may not be the most saleable good. This means those using a less marketable medium are hampered by the problem of double coincidence of wants to a greater extent than those using a more marketable medium. Thus we see that the tendency on the market is toward global commodity money for as Menger said (1892), "It lies in the economic interest of each trafficking individual to exchange less saleable for more saleable commodities.»

As Menger wrote in Principles of Economics (1871), "In the earliest periods of economic development, cattle seem to have been the most saleable commodity among most peoples of the ancient world... As society progressed, however, cattle became less and less marketable... With the progress of civilization, therefore, cattle lost to a great extent the broad range of marketability they had previously had with respect to the number of persons to whom, and with respect to the time period within which, they could be sold economically... They ceased to be the most saleable of commodities, the economic form of money, and finally ceased to be money at all... Peoples who were led to adopt a copper standard as a result of the material circumstances under which their economy developed, passed on from the less precious metals to the more precious ones, from copper and iron to silver and gold, with the further development of civilization, and especially with the geographical extension of commerce.»

Those who fight against this tendency will make less use of division of labor and, ceteris paribus, will accumulate less capital. A global commodity money best integrates division of labor, minimizes currency arbitrage and lessens obstacles to free trade. The Austrian theory of money thus demonstrates that the progression from a barter system to global commodity money represents increasing integration of division of labor and facilitates greater capital accumulation. The Hayekian deviants from Mengerian and Misesian theory, with their "competing currency» schemes, promote retrogression to a more primitive economy with greater double coincidence of wants, less division of labor and thus, ceteris paribus, greater poverty. As Murray Rothbard explains in The Case for a 100\% Gold Dollar (1991): 
Hayek and his followers have failed completely to absorb the lesson of Ludwig von Mises' "regression theorem,» one of the most important theorems in monetary economics... [F]or any commodity to become used as money, it must have originated as a commodity valued for some nonmonetary purpose, so that it had a stable demand and price before it began to be used as a medium of exchange. In short, money cannot be created out of thin air, by social contract, or by issuing paper tickets with new names on them. Money has to originate as a valuable nonmonetary commodity... Hayek's plan for the denationalization of money is Utopian in the worst sense: not because it is radical, but because it would not and could not work. Print different names on paper all one wishes, and these new tickets still would not be accepted or function as money; the dollar (or pound or mark) would still reign unchecked. Even the removal of the legal tender privilege would not work, for the new names would not have emerged out of useful commodities on the free market, as the regression theorem demonstrates they must. And since the government's own currency, the dollar and the like, would continue to reign unchallenged as money, money would not have been denationalized at all. Money would still be nationalized and a creature of the state; there would still be no separation of money and the state. In short, even though hopelessly Utopian, the Hayek plan would scarcely be radical enough, since the current inflationary and state-run system would be left intact... How, then, can the dollar be privatized or denationalized? Obviously not by making counterfeiting legal.

\section{II MONETARY CALCULATION}

Money makes rational economic calculation possible since all goods are priced in money, which then serves as a common denominator for all transactions, the generally used unit of account. As Mises explains in The Theory of Money and Credit (1912), «It would be absolutely impossible for the individual... to follow every change of market conditions and make the corresponding alterations in his scale of use -and exchangevalues, unless he chose some common denominator to which he 
could reduce each exchange-ratio. Because the market enables any commodity to be turned into money and money into any commodity, objective exchange-value is expressed in terms of money. Thus money becomes a price-index, in Menger's phrase. The whole structure of the calculations of the entrepreneur and the consumer rests on the process of valuing commodities in money. Money has thus become an aid that the human mind is no longer able to dispense with in making economic calculations.»

It is evident then that as a result of money being able to trade for everything in the market, goods in the market are naturally priced in that commodity money, whether it is expressed in ounces, pounds, kilograms, liters, or what have you. As Menger explains (1892), «[T] here was not only the reasonable prospect of his being able to convert them in all markets at any time and practically in all quantities, but also - and this is after all the criterion of saleableness - the prospect of converting them at prices corresponding at any time to the general economic situation, at economic prices.» Thus someone using the commodity money could reasonably expect their money to be accepted in trade at a price that represents its relative supply and demand compared to other goods in the market as judged by all the consumers.

The market selection of money must come from the vast majority of market participants, not just from individual assessments of marginal utility made by one person or a small group. Mises explains this very clearly in Socialism (1922), «In an exchange economy, the objective exchange value of commodities becomes the unit of calculation. This involves a threefold advantage. In the first place we are able to take as the basis of calculation the valuation of all individuals participating in trade. The subjective valuation of one individual is not directly comparable with the subjective valuation of others. It only becomes so as an exchange value arising from the interplay of the subjective valuations of all who take part in buying and selling. Secondly, calculations of this sort provide a control upon the appropriate use of the means of production. They enable those who desire to calculate the cost of complicated processes of production to see at once whether they are working as economically as others. If, under prevailing market prices, they cannot carry through the 
process at a profit, it is a clear proof that others are better able to turn to good account the instrumental goods in question. Finally, calculations based upon exchange values enable us to reduce values to a common unit. And since the higgling of the market establishes substitution relations between commodities, any commodity desired can be chosen for this purpose. In a money economy, money is the commodity chosen.»

Mises again explains this in Human Action (1940), «Thus money becomes the vehicle of economic calculation. This is not a separate function of money. Money is the universally used medium of exchange, nothing else. Only because money is the common medium of exchange, because most goods and services can be sold and bought on the market against money, and only as far as this is the case, can men use money prices in reckoning. The exchange ratios between money and the various goods and services as established on the market of the past and as expected to be established on the market of the future are the mental tools of economic planning. Where there are no money prices, there are no such things as economic quantities. There are only various quantitative relations between various causes and effects in the external world. There is no means for man to find out what kind of action would best serve his endeavors to remove uneasiness as far as possible.»

Mises again makes the point in Human Action (1940), "The acceptance of a new kind of money presupposes that the thing in question already has previous exchange value on account of the services it can render directly to consumption or production. Neither a buyer nor a seller could judge the value of a monetary unit if he had no information about its exchange value -its purchasing power- in the immediate past.» Likewise, Rothbard in Man, Economy, and State (1988) explains, "One of the important achievements of the regression theory is its establishment of the fact that money... must develop out of a commodity already in demand for direct use, the commodity then being used as a more and more general medium of exchange. Demand for a good as a medium of exchange must be predicated on a previously existing array of prices in terms of other goods...» Joseph T. Salerno summarizes the theory in Money, Sound and Unsound (2010), «Without going into great depth, the theory of the evolution of 
money as formulated by Carl Menger and later refined by Ludwig von Mises and Murray Rothbard tells us that the general medium of exchange originated on the market as the most saleable commodity in the pre-existing state of barter. Money thus initially circulated as a generic and unbranded commodity. The unit of account then naturally emerged as a standard weight unit of the money commodity that is most convenient for calculation, for example, pound, ounce, or gram.»

Despite the danger of repetition, I cite these multiple expositions of the theory in order to emphasize the point that the organic evolution of a commodity in to the most marketable commodity, money, must occur prior to its use as a medium of exchange in order for it to enable a rational unit of account, in order for the price structure to be formed. This seems necessary since the regression theorem is currently being misrepresented by Jeffrey Tucker, Robert Murphy, Detlev Schlichter, Peter Šurda and others, as will be discussed below. To have as Menger says «economic prices», prices that reflect the supply and demand of commodities across the entire market, they must be money prices. All goods must be priced in the most saleable good or they are very likely not economically priced. Money prices are organically formed ratios between money and each good on the market. These price ratios develop naturally as people increasingly adopted the money, for example one head of cattle might sell for one ounce of gold or three pigs for one ounce of gold, etc. These consumer set money price ratios are what enable rational economic calculation. As Rothbard explained (1991), they cannot be developed by trial and error once a medium of exchange is already in use.

Mises likewise explained in Epistemological Problems of Economics (1976) that without money prices, economic planners, whether public or private, are flying blind, «Without the aid of monetary calculation, bookkeeping, and the computation of profit and loss in terms of money, technology would have had to confine itself to the simplest, and therefore the least productive, methods.» Indeed, the existing structure of heterogeneous capital and technology could not even exist without money and rational economic calculation. In Liberalism (1927), Mises proclaimed, «Monetary calculation and cost accounting constitute the most important 
intellectual tool of the capitalist entrepreneur, and it was no one less than Goethe who pronounced the system of double-entry bookkeeping one of the finest inventions of the human mind.»

Without money prices, particularly in capital goods and interest rates, there is no rational guide for economic planning. Calculation chaos, shortages, surpluses, losses and bankruptcy must result. This was logically proven and predicted by Mises in «Economic Calculation in the Socialist Commonwealth» (1920), a prediction that was confirmed empirically, though empirical evidence cannot refute a priori theory, with the collapse of the USSR, for which he was taunted by Oskar Lange, «Both as an expression of recognition for the great service rendered by him and as a memento of the prime importance of sound economic accounting, a statue of Professor Mises ought to occupy an honorable place in the great hall of the Ministry of Socialization or of the Central Planning Board of the socialist state» (Rothbard, 1991).

But in the history of economics, Mises will have the last word. From Socialism (1922), "If the socialists attempt to belittle the significance of the problem of economic calculation... they simply show that they do not understand the real nature of the problem... there still remains the problem of ascertaining how the existing means of production can be used most effectively to produce these goods in question. In order to solve this problem it is necessary that there should be economic calculation. And economic calculation can only take place by means of money prices established in the market for production goods in a society resting on private property in the means of production. That is to say, there must exist money prices of land, raw materials, semimanufactures; that is to say, there must be money wages and interest rates.»

While there are no exceptions to the regression theorem, it has been possible for governments to forcibly substitute a token for commodity money after its rise, via legalized aggression, coercion and fraud. But this fiat currency could never have been implemented without the commodity money first creating an organic price structure. For instance, when the dollar's link to gold was broken by forcible demonetization, the paper dollar was able to use the gold price structure which existed the previous day. Mises (1912) explains, «This link with a preexisting exchange 
value is necessary not only for commodity money, but equally for credit money and fiat money. No fiat money could ever come into existence if it did not satisfy this condition.» Rothbard also explains in The Case for a 100\% Gold Dollar (1991), «How, then did such names as "dollar" and "peso" originate and emerge in their own right as independent moneys? The answer is that these names invariably originated as names for units of weight of a money commodity, either gold or silver. In short, they began not as pure names, but as names of units of weight of particular money commodities... I want to make it clear what I am not saying. I am not saying that fiat money, once established on the ruins of gold, cannot then continue indefinitely on its own. Unfortunately, ... if fiat money could not continue indefinitely, I would not have to come here to plead for its abolition.»

Salerno apparently coined the term "progression theorem» in «Money, Sound and Unsound» (2010) to describe this insight of Mises and Rothbard, saying «Rothbard builds on the work of Mises and Menger in formulating what may be called a "progression theorem" of fiat money, a historico-logical account of how paper fiat money can and does come into being only as the result of a long series of government interventions which progressively undermines the market-evolved commodity standard. One important implication of Rothbard's theorem for monetary reform is that there is no possibility of replacing a government monopolized fiat money with schemes for competing private inconvertible paper currencies. The reason is that the established fiat money, barring a hyperinflationary crackup, retains an indissoluble evolutionary link with the original commodity money by virtue of its position as the universally employed unit of price appraisement.»

III

\section{A PRIORI VS EMPIRICISM AND HISTORICISM}

To grasp Austrian monetary theory, it is imperative to understand that economic theory is a priori, is deducted from the pure logic of human action. As Mises says in Epistemological Problems of Economics (1976), «The science of human action that strives for 
universally valid knowledge is the theoretical system whose hitherto best elaborated branch is economics. In all of its branches this science is a priori, not empirical. Like logic and mathematics, it is not derived from experience; it is prior to experience. It is, as it were, the logic of action and deed.» The Austrian theory of the origin of money, the regression theorem and the progression theorem are no exception. They are not a historical description except in the sense that it must happen the way the theory describes, given the nature of economic law and reality. As Mises explains (1976), «New experience can force us to discard or modify inferences we have drawn from previous experience. But no kind of experience can ever force us to discard or modify a priori theorems. They are not derived from experience; they are logically prior to it and cannot be either proved by corroborative experience or disproved by experience to the contrary. We can comprehend action only by means of a priori theorems.»

And to make sure there can be no doubt, Mises chides the empiricists and historicists regarding the regression theorem in Human Action (1940), "Finally it was objected to the regression theorem that its approach is historical, not theoretical. This objection is no less mistaken. To explain an event historically means to show how it was produced by forces and factors operating at a definite date and a definite place. These individual forces and factors are the ultimate elements of the interpretation. They are ultimate data and as such not open to any further analysis and reduction. To explain a phenomenon theoretically means to trace back its appearance to the operation of general rules which are already comprised in the theoretical system. The regression theorem complies with this requirement. It traces the specific exchange value of a medium of exchange back to its function as such a medium and to the theorems concerning the process of valuing and pricing as developed by the general catallactic theory. It deduces a more special case from the rules of a more universal theory. It shows how the special phenomenon necessarily emerges out of the operation of the rules generally valid for all phenomena. It does not say: This happened at that time and at that place. It says: This always happens when the conditions appear...» 
In conclusion, the Austrian theory of money proves that only a pre-existing commodity traded across the entire global market can become money in the modern economy and only by an organic process driven by the majority of consumers making market exchanges. Jesús de Soto summarizes in Money, Bank Credit, and Economic Cycles (1998), "It is impossible to take a leap in the dark and establish an artificial monetary standard which has not emerged through an evolutionary process.» And Salerno, in «Money, Sound and Unsound» (2010), reiterates: «Currency competition can only emerge out of an evolutionary market process and cannot be implemented in one fell swoop by legal fiat or by a private entrepreneurial scheme.»

IV

\section{APPLICATION TO BITCOIN}

In «The Austrian Influences on Bitcoin» (March 25, 2014), Jeffrey Tucker claims Bitcoin needed only to be used by a small group of people prior to use as medium of exchange in order to satisfy the regression theorem. Tucker says (2014), «Users played around with the results for fully 8 months before the attached currency (Bitcoin) obtained its first market value... It was released not as a traditionally capitalist product but rather on a free forum. Anyone could download it and starting [sic] "mining" Bitcoin... In fact, if there were no payment network bound up with the currency, the currency itself would have no value at all.» Peter Šurda quotes another Bitcoin fan, Mike Hearn, making the same admission in a speech posted online here: (https: / soundcloud.com/mindtomatter/conference-2013-mike-hearn), «I found it very early on, when noone [sic] was using it, so noone [sic], no exchanges, had no exchange rate at all, so they were just completely floating in an abstract space. You know, what was one coin? Well, nothing really.»

So we see that Tucker and Šurda directly concede that neither Bitcoin itself nor the "payment system» had a market price prior to being used as a medium of exchange. And if Bitcoin had no market price, there were no consumer set price ratios to the other 
market commodities, no price structure. Without a price structure, there can be no monetary calculation and thus very limited division of labor. So we see that pointing to the commodity price of Bitcoin after it was being used as a medium of exchange does not satisfy the regression theorem's requirements for the development of sound money. A medium of exchange must first be a commodity if it is to become money, and this order cannot be reversed. As North says in «I, Broken Pencil» (December 06, 2013), «But the programmers think they can reverse the regression theorem.» So either Tucker fails to understand the requirement for a pre-existing commodity price or believes this praxeologically necessary, chronological order of development can be altered via «trial and error» after the medium of exchange is in use. This would be a rejection of Mengerian, Misesian and Rothbardian theory described above in the Monetary calculation section. In any case, his assertion that Bitcoin satisfies the regression theorem is clearly erroneous.

In What gives money value, and is fractional-reserve banking fraud? (March 19, 2012), Detlev Schlichter, taking a different tack, claims, «But equally it [Bitcoin] is commodity money because it is based on a cryptographic algorithm, which requires time and considerable computing energy to create Bitcoins and which is designed so that the overall supply of Bitcoin is strictly limited.» And similarly, in Šurda's master's thesis (2012), he says, «According to my opinion, the rational expectations of the potential utility of Bitcoin for the potential buyers exceeded the price demanded by the producers, and trade emerged.» But again, neither the cryptographic algorithm, nor the computer time involved, nor any expectations of potential buyers had a market price prior to Bitcoin's use as a medium of exchange. Likewise, pointing to the use of ink, electricity, a printing press, or computers in producing fiat dollars does not satisfy the regression theorem's requirement for the medium itself to have first been a pre-existing commodity.

Instead the fiat dollar's ability to serve for rational economic calculation derived from the gold dollar via the progression theorem, or as Hans-Hermann Hoppe called it in «How is Fiat Money Possible?» (1994), «a theory of the devolution or destruction of money by government.» But, unlike the fiat dollar, Bitcoin did 
not exist at the time gold was forcibly demonetized by the state and thus could not absorb the gold price structure, as the dollar did. Since Bitcoin has no price structure of its own, it is clearly dependent on the price structure of the dollar and its convertibility into and out of dollars. No fiat dollar, no price structure, no Bitcoin.

As Shostak says in the «Bitcoin Money Myth» (2013), «Bitcoin can function only as long as individuals know that they can convert it into fiat money, i.e. cash on demand.» And "Besides, Bitcoin is not a new form of money that replaces previous forms, but rather a new way of employing existent money in transactions. Because Bitcoin is not real money but merely a different way of employing existent fiat money, obviously it cannot replace it.» And as Nikolay Gertchev says in «The Money-ness of Bitcoins» (April 04, 2013), "After all, a very limited set of items can be purchased with bitcoins, and sellers still price their goods in dollars, euros, etc. The price is then converted into bitcoins, according to the prevailing exchange rate, at the final stage of finalizing the payment method of the transaction. Thus, while bitcoins do appear to serve as a means of payment, they are definitely not used yet for business calculation.» And clearly they can never be used for it, per the regression theorem.

Like Tucker and Šurda, Robert Murphy in «On Bitcoin and Ludwig von Mises' Regression Theorem» (March 10, 2014), concedes that Bitcoin had no pre-existing commodity price but repudiates the regression theorem, believing falsely that Bitcoin has refuted it empirically, «I will make the modest point that if Mises is used to rule out Bitcoin's acceptance as money, then it seems that Mises has already lost. If this logic is correct, then Bitcoin should never have been adopted as even a medium of exchange because it served no useful role as a regular commodity. (Recall that money is simply a medium of exchange that is accepted by everyone in the community.) But Bitcoin has already surpassed that hurdle, as there are websites on which people from all over the world exchange their Bitcoins directly for goods and services.»

Indeed, Murphy admits the assertion that the regression theorem applies to any medium of exchange is just his own interpretation based on what he views as «the inner logic of the 
regression theorem $»$ : https://www.youtube.com/watch?feature= player_detailpage\&v $=w y U N d z L w t e 4 \# t=996 \mathrm{~s}$. But the proper interpretation of the regression theorem as covered above is not that something can never become a medium of exchange if it wasn't first a commodity but rather that it cannot become the generally accepted medium of exchange unless it was first a commodity. Only a generally traded commodity can become a generally accepted medium of exchange, money. Money is the commodity which allows monetary calculation concerning every other good in the economy.

Murphy even concedes the fact that money is not just a medium of exchange in the parenthetical statement quoted above. Yet in his video, Murphy cites the fact that Mises was not always exacting in describing money as the generally accepted medium of exchange or most marketable good but sometimes said only that money was simply a medium of exchange. This is perfectly true. But it is easily explained by the fact that Mises was not discussing monetary calculation in these statements but rather the catallactic impact of inflation, which is any increase of any medium of exchange. His point was that inflation has the same economic effects regardless of whether a medium was widely used or not, namely redistribution, malinvestment and potentially boom and bust cycles if the use of the medium of exchange is wide enough. Indeed, in his book Lessons for the Young Economist (2010), Murphy defines money as, «A good that is accepted by everyone in the economy on one side of every trade. In economics jargon, it is a widely (or universally) accepted medium of exchange.»

As Mises pointed out and has been described above, the difference between a medium of exchange and money is one of degree. Inflation of money will have far wider impact on the economy than inflation of some niche medium of exchange used by a small group. This in no way impacts the regression theorem requirement for money to first be a pre-existing commodity. Clearly Mises was not saying that, for example, two irrational people could not use a non-commodity for indirect exchange. Two people could use monopoly game paper for a medium of exchange but this does not make monopoly game paper money, does not create a market- 
wide price structure. It is of course possible that Mises also simply made a mistake at some point and neglected to include the "generally accepted» modifier to the definition of money. I have not checked the context of every such statement, obviously. But to take this as proof he saw no distinction would be absurd since he draws the distinction many, many times. And because it is a difference of degree does not make it a difficult distinction to draw. With Bitcoins, there are very few places one can go buy commodities, even converted to dollars at the point of sale, while with dollars one can pretty much go everywhere and buy just about anything being sold.

We can witness further confusion from Murphy (March 10, 2014), where he says, "I concluded that even though there is a superficial tension, Mises' regression theorem really has no bearing today on whether Bitcoin has the ability to become money... So, what relevance does this have to Bitcoin? The short answer: none whatsoever. There is no question that people today have a way of estimating the purchasing power of Bitcoin; they can look up the spot price online. If we object that the current price is largely dependent on yesterday's price, then we start back with the regress. And where do we stop?» But clearly the spot price in dollars is not independent of the dollar price structure. The fact that Bitcoin has a price in dollars does not demonstrate that it is has a price structure independent of the dollar to all other or most other market goods.

Murphy continues, "If Austrian economists want to say, "But those people had no basis for saying whether that pizza should have been 100 BTC or 1 million BTC!!" OK fair enough. But they did decide, somehow; those initial transactions provided a frame of reference that guided subsequent transactions involving Bitcoins. If you want to argue that this odd origin means that subjective value theory can't be applied to Bitcoin, OK, then so much the worse for subjective value theory.» But, again, he misses the point. The fact that someone paid a certain dollar price in Bitcoins for a particular commodity does not demonstrate that the price was an economic price, a price representing real supply and demand factors across the global market, nor does it indicate the Bitcoin itself has a price ratio to other commodities. 
Murphy then rejects the Mengerian, Misesian, Rothbardian theory of money outright saying, "In conclusion, Ludwig von Mises' regression theorem has nothing to say about the empirical question of whether Bitcoin will move beyond a medium of exchange and become a true money.» Similarly, in Bitcoin for Beginners (April 02, 2013), Tucker says, «Understanding Bitcoin requires that we understand the limits of our ability to imagine the future that the market can create for us.» But, as we have covered above, there are no exceptions to the regression theorem and it is a priori, not empirical. The regression theorem has everything to say about what can and cannot become money.

Similar to these failed efforts to argue that Bitcoin satisfies the regression theorem requirement is Graf's argument in «INDEPTH | Bitcoins, the regression theorem, and that curious but unthreatening empirical world» (February 27, 2013) where he claims, «Thus, even if every single interpreter, including myself writing now, were to end up failing to find any prior direct-use or direct-exchange values, we would still know that bitcoins had had one. All that we would establish by not finding one would be the failure of our own interpretive efforts. That said, I will now proceed with my own attempt at such an interpretation along several lines... I might also want a bitcoin for any reason I feel like having one. I might want to just study it and see how it works or collect it as a virtual souvenir or trophy. I might want to use some of its code string as T-shirt art. I might want to stay up nights trying to crack the system because it's there, like the proverbial unclimbed mountain. I may just want to feel cool and smart by having a bitcoin and telling friends about it. None of these purposes constitutes an indirect-exchange purpose. These are all direct uses.»

But, again, the fact that a small group of individuals found value in Bitcoin prior to its use as a medium of exchange, for whatever reason, rational or irrational, is totally irrelevant since it did not have a market price. So, no, the fact that Bitcoin is used as a medium of exchange now in no way proves it can become a money and serve for rational monetary calculation. A group of people could value dog poop for the odor but this in no way means dog poop has a market-wide price and thus could become 
money, though it could indeed serve as a medium of exchange, as can probably just about anything, at some scale.

«In Bitcoins: The Road to Investment Hell Is Paved With Good Intentions». (December 03, 2013), Gary North also makes this point very clearly, «The defenders of Bitcoins must deny the MengerMises regression theorem. They must affirm what Hayek called constructivist rationalism: the imposition of a man-made plan to create a new social order.» And in «I, Broken Pencil» (December 06, 2013), he points out, «The problem for the defender of Bitcoins is this: we need a comprehensive system of prices. For Bitcoins to work, they must be autonomous from the fiat money pricing system of the various government currencies... It is not possible to run Bitcoins as a separate currency system unless it applies to every product, every transaction, every service that is presently priced in terms of government monetary systems. Why is this? Because the division of labor must be integrated by a single currency system. In order to make the pencil, everything must be priced in terms of Bitcoins: paint, wood, carbon, rubber, metal, and every raw material and every piece of capital equipment that was used to make the pencil. This is the whole point of [Leonard] Read's thesis. There has to be universal pricing. There has to be a profit-and-loss system governed by the universal pricing system in an integrated currency system.»

As North says in «Showdown: Bitcoins vs. Greenbacks» (December 10, 2013), «The only way you can buy anything with Bitcoins is because the seller is going to convert the Bitcoins immediately into dollars... Therefore, hardly anyone is going to sell you anything for Bitcoins who does not have the ability to convert instantly those Bitcoins back into dollars or his own domestic currency... So, for a retail establishment to be willing to sell you anything for Bitcoins, it must have a computer program tied to its bank in order to convert Bitcoins into dollars instantaneously. This means that the retail seller has to let his bank know that he is using Bitcoins. This means that, at any time, the Federal Reserve System can collapse the price of Bitcoins... Therefore, with respect to marketability, Bitcoins are an extension of the central banking system. They are in no way independent of the central banks. The Bitcoins market operates only at the discretion of the 
central banks. The central banks allow Bitcoins for the moment, and only because of this toleration by the central banks does any market for Bitcoins exist.»

Surprisingly, «In Bitcoin for Beginners» (April 02, 2013), Tucker says, "After one full day of buying, selling, and using Bitcoins, I had the strange experience of resenting that I had to pay a cab fare in plain old U.S. dollars.» This is exactly on point since Bitcoin is not money and thus using it introduces greater problems with double coincidence of wants. This will always be the case with Bitcoin. Likewise, Graf admits (February 27, 2013), «Even Bitmit, a dedicated bitcoin-denominated auction site, automatically and helpfully translates all bitcoin prices into the local fiat currency instantly customized for visitor location after the bitcoin price.» He again makes the concession in (September 14, 2013), «Those who pay in Bitcoin today overwhelmingly pay prices that are listed in the local fiat currencies of the politically-defined jurisdictions they find themselves trading within. There are already a few exceptions, such as the Trezor high-security hardware wallet (priced at 1 bitcoin) and some mining shares, but such examples remain rare.»

Also, in Tucker's (2014) section labeled Israel Kirzner, he claims, "But only those super-alert to the opportunity ["mining" Bitcoins] did so. One of those was the inventor himself, who is a very rich person today. This is what it means to be alert to and discover an opportunity.» Superficially, this seems fine. But it further indicates Tucker's failure to grasp the true nature of entrepreneurship and the necessity of rational monetary calculation. And I quote Rothbard (1991), "For Hayek and for Kirzner, the market is a "discovery procedure," that is, an unfolding of knowledge. There is, in this view of the market and of the world, no genuine recognition of the entrepreneur, not as a "discoverer," but as a dynamic risk taker, risking losses if his appraisal and forecast go awry. Kirzner's commitment to the "discovery process" fits all too well with his own original concept of the entrepreneurial function as being that of "alertness," and of different entrepreneurs as being variously alert to the opportunities that they see and discover. But this outlook totally misconceives the role of the entrepreneur. The entrepreneur is not simply "alert"; he forecasts; he appraises; he 
meets and bears risk and uncertainty by questing for profits and risking losses.»

Finally in regards to the pro-Bitcoin literature online, I must address several rather strange references from Peter Šurda's articles. In «Re: Bitcoin Bubble 2.0» by Patrik Korda (March 6, 2013), He says, «Similarly as in the section about the regression theorem, Korda conflates medium of exchange (whatever is used in indirect exchange) and money (the most liquid good, and thus by implication, the most liquid medium of exchange).» Surda goes on to emphasize the importance of liquidity to money in this article saying, "Contrary to this dichotomy, there is a wide range on the liquidity scale which is called "secondary media of exchange"... that do provide, through liquidity, useful services.»

But, again, Austrian monetary theory emphasizes the importance of saleability-marketability, not liquidity. Whatever he means by liquidity, if it is a factor in the market selecting money then it is already folded within saleability-marketability, which includes all of a commodity's characteristics. Indeed in «The classification and the future of Bitcoin» (another Re: Patrik Korda) (March 12, 2013), Šurda even quotes Rothbard opposing the use of liquidity in the definition of money, «The current tendency of some economists to include assets as money purely because of their liquidity must be rejected; after all, in some cases, inventories of retail goods might be as liquid as stocks or bonds, and yet surely no one would list these inventories as part of the money supply. They are other goods sold for money on the market.»

Then in «I, Broken Economist: An Analysis of Gary North's economics of Bitcoin» (December 7, 2013), Šurda says, «Because [Gary] North does not have a general theory of liquidity, and a general theory of transaction costs [sic]. Which is very sad, because Menger was very eloquent on explaining both of these categories and made profound discoveries [sic]. People who claim that their arguments are based on Menger, yet do not have either a theory of liquidity or a theory of transaction costs do not really understand Menger.» Later Šurda goes on to rant, «[Gary] North complains that people who criticise his position of Bitcoin do not understand the Austrian school. Well, I know for sure that North does not understand certain aspects of it (in particular Menger's approach 
to liquidity and transaction costs), and on other aspects he can't connect the theory with empirical data. He's also lazy (because he did not read Austrian literature on Bitcoin and he did not gather empirical data on Bitcoin), and conceited (because he thinks his credentials give him immunity from errors).» Also in the March $6^{\text {th }}$ article, Šurda says, «Bitcoin's further advantage is the decrease of transaction costs, which can be practically utilised as long as some level of liquidity persists... The relevant question is if Bitcoin decreases transaction costs, and the answer is that it does. Whether the price changes are a bubble or not does not change the answer to the question whether it has a comparative advantage against other media of exchange... Almost all critiques of Bitcoin entirely ignore transaction costs.»

I have no idea where Šurda's definition of money as the most liquid good came from as there is no citations for its use in any of Šurda's writings that I can find and very few citations of any kind in his work. However, the emphasis on liquidity and transaction costs does not appear to come from Carl Menger. As far as I can tell searching Menger's books Principles of Economics (1871), Investigations Into the Method of the Social Sciences (1883), and On the Origins of Money (1892), he never even used the terms, though the translator of Principles of Economics did use liquidity once in his preface, but not in reference to Menger. Finally, Surda repeatedly uses the term «network effect» in both of the above cited articles, seemingly to point to the manner in which one good becomes more saleable than others as described in the first section of this paper. But where does this term come from and does he really mean the same thing? We don't know since there is again no citation. But it does not appear to directly refer to the Mengerian theory of saleableness since I again found no use of the phrase in Menger's books. And in any case, saleabilitymarketability covers all characteristics of a commodity. As Hans F. Sennholz explains in «The Monetary Writings of Carl Menger» (1985), «In Menger's time many writers were eager to add secondary functions to that of medium of exchange. They spoke of money facilitating credit transactions or transmitting value through time and space. Or they dwelt on money as a general medium of payment. But Menger showed convincingly that all secondary 
functions can be deduced from the function of money as common medium of exchange.»

\section{$\mathrm{V}$ \\ WHAT IS BITCOIN?}

Since Bitcoin was not a pre-existing commodity before being used as a medium of exchange, it is in fact inflation, counterfeit, pyramiding on top of the fiat dollar. Bitcoin is an expansion of the medium of exchange with an alleged promise to stop inflating someday. And as Rothbard explained in Making Economic Sense (1995), «For monetary inflation is counterfeiting, plain and simple. As in counterfeiting, the creation of new money simply diverts resources from producers, who have gotten their money honestly, to the early recipients of the new money-to the counterfeiters, and to those on whom they spend their money.»

Thus as Rothbard explains in What Has Government Done To Our Money? (1963), «Inflation, then, confers no general social benefit...» All the capital spent on Bitcoin «mining» and the like is malinvestment. It is a symptom of the destruction of the international gold coin standard and the failure to enforce $100 \%$ gold reserves. It is an atomization of the monetary system as Mises described, a breakdown of international division of labor. As Gary North summarizes in «I, Broken Pencil» (December 06, 2013), «Without a monetary system, the division of labor simply collapses.» And Bitcoin is still inflating, along with imitations such as Litecoin, Zerocoin and apparently many others. As Patrik Korda says in Bitcoin Bubble 2.0: «From A Monetary Standpoint-It's On Par With The Stuff You Find At Chuck E. Cheese's» (March 28, 2013), «While bitcoins cannot be hyperinflated in name, they certainly can be hyperinflated in substance.»

Interestingly enough, Tucker (March 25, 2014) says, «In essence, the government grants banks the right to counterfeit so long as government can enjoy the first fruits of the printing press.» But what makes the fiat dollar counterfeit? Like Bitcoin, it was not a pre-existing commodity prior to being used as a medium of exchange. As David Kramer quips in «Bitcoin: Just Another Bogus 
Medium of Exchange» (June 9, 2011), «Bitcoin is just substituting one bogus medium of exchange for another.» Korda warns us in «Bitcoin: Money of the Future or Old-Fashioned Bubble?» (April 09, 2013), «Let us not become so enamored of an innovative stateless solution that we forget Austrian economics and hitch libertarianism's wagon to something heading for a crash.» And Rothbard in "Irrepressible Rothbard» (2000) sums the situation up very nicely, "Just call it "free trade," and free-market economists and libertarians will swallow anything.»

\section{VI \\ CONCLUSIONS}

Since Bitcoin was not a pre-existing commodity with a marketwide price, since it has no consumer created price structure to all or most other goods, it cannot ever serve for rational economic calculation. Thus it cannot become money, cannot separate money from the state and cannot end the state as many have suggested like Michael Suede in "Could The State Exist If Property Rights Were Impossible To Violate?» (July 1, 2011) and Peter Surda in «Re: Bitcoin Bubble 2.0» by Patrik Korda.

As Jesús Huerta de Soto in a personal email writes, "The possibilities the bitcoin becomes money are null and Mises' regression theorem explains why: money is an evolutionary, organically formed institution that cannot be created ex novo.» And even Murphy (2010) says, «The institution of money is a classic example of what Austrian economist Friedrich Hayek called a spontaneous order, meaning that the use of money is a very complex and useful practice, even though it was not consciously planned by an expert or even a group of experts.» Yet Bitcoin was centrally planned, allegedly created by one man.

Bitcoin is counterfeiting, inflation, theft conducted by fraud, misrepresentation through complication, just like the fiat federal reserve system, though to a far lesser extent. It is inflationists saying, «We can counterfeit-inflate and its fine, but the state can't do it or its evil!» Jesús de Soto explains the inevitable consequences in Money, Bank Credit, and Economic Cycles (1998), «The very 
definition of money reveals that any manipulation of it, society's universal medium of exchange, will exert harmful effects on almost all third-party participants throughout the economic system. Therefore it does not matter whether or not depositors, bankers, and borrowers voluntarily reach specific agreements if... such agreements influence money and harm the public in general (third parties). Such damage renders the contract null and void, due to its disruption of the public order. Economically speaking, the qualitative effects of credit expansion are identical to those of the criminal act of counterfeiting banknotes and coins... Both acts entail the creation of money, the redistribution of income in favor of a few citizens and to the detriment of all others, and the distortion of the productive structure. Nonetheless, from a quantitative standpoint, only credit expansion can increase the money supply at a fast enough pace and on a large enough scale to feed an artificial boom and provoke a recession. In comparison with the credit expansion of fractional-reserve banking and the manipulation of money by governments and central banks, the criminal act of counterfeiting currency is child's play with practically imperceptible social consequences.»

The Soviet Union, just like the Bitcoin supporters, scoffed at gold, the regression theorem and the Misesian economic calculation problem, even gloried in their assumed defeat of these economic laws, and Bitcoin will go the same way, to the dust-pile of history. As Mises proclaimed in «The Causes of the Economic Crisis» (1923), «Inflationists of every variety must be completely demolished. We should not be satisfied to settle for compromises with them. The slogan, «Down with gold," must be ousted. The solution rests on substituting in its place: «No governmental interference with the value of the monetary unit!» And as Robert A. Heinlein summarized in The Moon Is a Harsh Mistress (1966), «TAANSTAFL!» In conclusion, I would just say there are many other obvious problems with Bitcoin that were outside the scope of this paper focusing on the issue of monetary calculation. 
